\title{
Van İli Tarım Alanlarında Temiz ve Atık Su Kaynaklarının Yönetimi
}

\author{
Talip ÇAKMAKCI ${ }^{*}$, Üstün ŞAHİN ${ }^{2}$, Yasemin KUŞLU ${ }^{2}$, \\ Fatih Mehmet KIZILOĞLU ${ }^{2}$, Şefik TÜFENKÇí1, Mustafa OKUROĞLU ${ }^{2}$
}

\author{
1: Yüzüncü Y1l Üniversitesi, Ziraat Fakültesi, Biyosistem Mühendisliği Bölümü, Van, Türkiye \\ 2: Atatürk Üniversitesi, Ziraat Fakültesi, Tarımsal Yapılar ve Sulama Bölümü, Erzurum, Türkiye \\ *e-posta: talipcakmakci@yyu.edu.tr
}

Özet: Van ili toprakları $19.069 \mathrm{~km}^{2}$ alan ile Türkiye topraklarının \% 2.5'ini oluşturmakta ve bu toprakların yaklaşı 374.500 ha alanı tarım arazisi konumunda bulunmaktadır. Tarım arazisinin 260.000 ha'ya yakın alanı sulanabilir nitelikte olmakla beraber bu alanında \%50'si sulanabilmektedir. Sulanamayan alanlar için su kalitesinin düşük olması, sulama suyunun yetersiz kalması, suyun tarlaya ulaştırılmasındaki güçlükler ve kapalı taşıma sistemi için yatırım eksikliği sınırlandırıcı faktörler olarak sayılabilir. İl sınırlarında 1'i inşaat halinde toplam 4 baraj gölü, 15'a yakın göl-gölet bulunmaktadır. Atık su potansiyeli olarak, İl genelinde bulunan arıtma tesislerinin 5 tanesi aktif olarak arıtım yapmakta, 2 tanesinin de inşaatı sürmektedir. Van ili kanalizasyon hattı ile yıllık 60 milyon ton atık su Van Gölüne ve akarsulara deşarj edilmektedir. Bu suyun tarımsal amaçlı kullanılmasıyla sulanamayan alanlara bir miktarda olsa sulama suyu sağlanabilecektir. Bu çalışmada Van ilinin mevcut su durumu ile tarımsal alanlarda sulama suyu ve atık suyun kullanım potansiyelinin ortaya konması amaçlanmıştır.

Anahtar kelimeler: Atık su kullanımı, Su kaynakları, Sulama suyu yönetimi, Tarım alanları

\section{Management of Clean Water and Wastewater Sources in Van Agricultural Areas}

Abstract: Van province territory constitutes 2.5\% of Turkey' land with land of $19.069 \mathrm{~km}^{2}$ and is located in a position approximately 374.500 hectares of agricultural land. Although having potentially for irrigation, only $50 \%$ of the agricultural land $(260.000 \mathrm{ha})$ colud be irrigated. For non-irrigated areas, the low quality of water, inadequate irrigation water, and difficulties in delivering water to fields and lack of investment for the closed transport system can be considered as limiting factors. Total 4 dam lakes (reservoir), including one under constructions and nearly 15 lakes and ponds are situated in the provincial border. As waste water potential, treatment plants in city have been active in 5 of them and 2 of them are under construction. Annually 60 million tons of sewage waste water is discharged into rivers and Lake Van by Van province sewer line. By using this water for agricultural purposes, a certain amount of water will be provided to non-irrigated areas. In this study, with the current water situation in agricultural areas of Van province potential use of irrigation water and waste water.

Keywords: Agricultural areas, Irrigation water management, Wastewater use, Water resources

\section{Giriş}

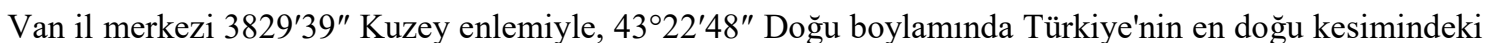
bölgede yer alır. Van, kuzeyden Ağrı İli'nin Doğubeyazıt, Diyadin, Hamur İlçeleri, batıdan Van Gölü ile Ağrı İli'nin Patnos, Bitlis İli'nin Adilcevaz, Tatvan ve Hizan İlçeleri, güneyden Siirt İli'nin Pervari İlçesi, Şırnak İli'nin Beytüşşebap İlçesi ve Hakkari İli'nin Yüksekova İlçesi ile sınırlıdır. İlin doğusunda ise İran yer alır. Van'ın iklim özelikleri karasal iklim tipi gösterse de ortasında küçük bir deniz karakteri gösteren Van Gölü'nün bulunması iklimin yumuşak geçmesine sebep olmaktadır (Anonim 2006). Van ili uzun yıllar yağış miktarı ortalaması 387.4 mm'dir. Meteoroloji Genel Müdürlüğü verilerine göre yoğun sulama sezonu olan Haziran-Temmuz-Ağustos aylarındaki yağış miktarı toplamı 27.6 mm'dir (Anonim 2015a). $\mathrm{Bu}$ rakam bitkisel üretim için oldukça yetersizdir. Bu sebeple de yüksek verim almak için üretim sezonunda sulama yapılması zorunlu hale gelmektedir (Ertek ve ark. 2004, 2006; Sensoy ve ark 2007). 
Ülkemizde tarımsal yapının gelişmesi için alınacak tedbirler içerisinde arazi kullanma düzeninin yanında toprak ve su kaynaklarının etkin bir şekilde kullanılması ve korunması gelmektedir. Bu yüzden yapılacak çalışmalar su, toprak ve bitki yetiştirme bilimleriyle birleştirilerek etkin hale getirilmelidir. Toprak; insan, bitki ve hayvanlar için besin kaynağı, su ise; canlı varlıkların büyümesi, gelişmesi ve çoğalması için zorunlu öğedir. Bu yüzden toprak- su- bitki ilişkisi iyi bilinmeli ve iyi bir denge kurulmalıdır (Tekinel 2004).

Türkiye'nin 77. 95 milyon ha olan yüzölçümünün yaklaşık 28.05 milyon hektarlık kısmı ekilebilir nitelikte olup bu alanında 25.85 milyon hektarı sulanabilir arazilerden oluşmaktadır. Fakat ekonomik olarak sulanabilir alan 8.5 milyon hektar olarak hesaplanmıştır. Uluslararası standartlara göre bir ülkenin su zengini sayılabilmesi için kişi başına düşen su miktarı $10000 \mathrm{~m}^{3} / \mathrm{y} 1 \mathrm{l}$ olması gerekmektedir (Turan 2002). Fakat mevcut kaynaklarımız ile Türkiye'de kişi başına düşen su miktarı $1400 \mathrm{~m}^{3} / \mathrm{y} 1 \mathrm{l}$ olarak hesaplanmıştır. Yapılan araştırmalara göre son 40 yılda su tüketimi 2 kat artış göstermiştir. Bununla birlikte önlem alınmadığı takdirde gelecekte ülkemiz olarak büyük sıkıntılar yaşanacağı aşikârdır (Akın ve Akın 2007; Sağlam ve Bellitürk; 2003; Eryılmaz ve Ark. 2014).

\section{Van İli Arazi Varlı̆̆ı ve Kullanımı}

Van ilinde çeşitli toprak türleri bulunmaktadır. İlin kuzey kısımlarında kahverengi topraklar, doğu kesimlerinde ise kestane rengi ve kahverengi topraklar bulunmaktadır. Bu topraklar Van ili toplam toprağının \%60'ını kapsamaktadır. Van ili arazi varlığı 1.906 .900 ha olup bu alanın 374.384,2 ha'ı tarım arazisi niteliğindedir (Çizelge 1).

Çizelge 1. Van İli ve İlçelerinde arazi dağılımı ve kullanımı (Anonim 2016a)

\begin{tabular}{lrrrrr}
\hline İlçeler & $\begin{array}{r}\text { Toplam } \\
\text { alan (ha) }\end{array}$ & $\begin{array}{r}\text { Sulanan alan } \\
\text { (ha) }\end{array}$ & $\begin{array}{r}\text { Sulanmayan } \\
\text { alan (ha) }\end{array}$ & $\begin{array}{r}\text { Nadas } \\
\text { alanı (ha) }\end{array}$ & $\begin{array}{r}\text { Tarıma elverişli } \\
\text { olup kullanılmayan } \\
\text { alan (ha) }\end{array}$ \\
\hline Bahçesaray & $5.942,70$ & $1.638,30$ & 1,10 & 39,70 & $3.746,00$ \\
Baškale & $42.108,70$ & $25.252,80$ & $4.705,00$ & $9.732,50$ & $2.408,70$ \\
Çaldıran & $27.620,10$ & $8.474,80$ & $6.624,10$ & $10.030,30$ & $2.483,00$ \\
Çatak & $20.443,10$ & $10.708,40$ & $4.920,00$ & $1.680,10$ & $2.249,60$ \\
Erciş & $56.077,90$ & $9.452,40$ & $13.659,00$ & $18.564,00$ & $12.945,00$ \\
Gevaş & $7.656,40$ & $5.727,20$ & $1.035,20$ & 100,00 & 17,60 \\
Gürpınar & $49.394,70$ & $15.138,60$ & $25.326,00$ & $6.796,00$ & $2.078,10$ \\
Muradiye & $37.352,00$ & $11.549,00$ & $6.148,60$ & $14.321,80$ & $5.000,00$ \\
Özalp & $32.971,50$ & $3.825,00$ & $13.605,00$ & $13.578,30$ & $1.961,70$ \\
Saray & $9.436,00$ & $5.120,00$ & $1.245,00$ & $1.194,50$ & $1.875,00$ \\
Edremit & $12.367,90$ & $4.000,00$ & $3.257,00$ & $1.691,00$ & $1.836,90$ \\
İpekyolu & $43.820,20$ & $6.273,00$ & $6.999,60$ & $7.493,00$ & $7.700,00$ \\
Tuşba & $29.193,00$ & $9.260,70$ & $8.990,00$ & $12.918,00$ & $12.000,00$ \\
\hline Toplam & $\mathbf{3 7 4 . 3 8 4 , 2 0}$ & $\mathbf{1 1 6 . 4 2 0 , 2 0}$ & $\mathbf{9 6 . 5 1 6 , 2 0}$ & $\mathbf{9 8 . 1 3 8 , 4 0}$ & $\mathbf{5 6 . 3 0 1 , 6 0}$ \\
\hline
\end{tabular}

Van İli arazi varlığının 403.212 ha olduğu sulanabilir alanın 88.578 ha olduğu yapılan çalışmalarda ifade edilmiştir (Gözütok 1993; Ertek ve ark. 2000). Son yıllardaki veriler incelendiğinde ise tarım alanının $374.384,2$ ha olduğu ve sulanan alanın da $116.420,2$ ha olduğu görülmektedir. Bu iki veri karşılaştırıldığında yıllar içerisinde arazi varlığının bazı sebeplerle (nüfus artışı, yerleşim yeri, kamulaştırma vb.) azaldığı sulanabilir arazinin ise gelişen teknoloji ve imkânlar dâhilinde artış gösterdiği söylenebilir.

TUIKK verileri incelendiğinde son 5 yıllık periyotta tarım alanlarının yaklaşık olarak aynı büyüklükte kaldığı görülmektedir. Fakat meyveler, içecek ve baharat bitkileri ekim alanı bir önceki yıla göre hep artış göstermiştir. Bu da sulu tarımın arttığını göstermektedir. Ayrıca Van ili tarım alanlarının büyük kısmında dünyada ve ülkemizde temel besin kaynağ 1 olan ekmeklik buğday yer almaktadır (Kaydan ve Yağmur 2008). Van ili topraklarına bakıldığında Çimrin ve Boysan (2006)'ın yaptıkları çalışmada Van ilinde buğday tarımı yapılan Van topraklarının besin elementi açısından yeterlilik seviyelerine göre sınıflandırmışlardır. Sonuç olarak toprakların $\% 11.5$ i azotça fakir, $\% 36.5$ ' i orta, $\% 46.0$ 'si iyi ve $\%$ 6's1 zengin durumda iken, toprakların büyük bir çoğunluğunun fosfor ve alınabilir çinko açısından gübrelemeye ihtiyaç duyduğunu belirtmişlerdir. Ayrıca Tüfenkçi ve ark, (2009) yılında Van ili bağlarının 
beslenme durumlarının belirlenmesi amacıyla yaptıkları çalışmada bölge toprak özelliklerinin genellikle kumlu killi tın, kumlu tın, kumlu kil olduğunu belirtmişlerdir.

\section{Van İli Su Kaynakları ve Kullanımı}

Van ilinde sulanabilir nitelikteki $256.121,1$ ha tarım arazisinin $116.420,2$ ha sulanmaktadır. Sulanan alanın, tarım alanı içindeki oranı \% 31 'dir (Çizelge 2).

Çizelge 2. Van İli tarım arazilerinin sulama durumu (Anonim 2014; 2016a)

\begin{tabular}{lrc}
\hline Arazi sınıfi & Alan (ha) & Toplam tarım arazisine oranı (\%) \\
\hline Toplam kültür arazisi & $374.384,2$ & \\
Sulanabilir arazi & $256.121,1$ & 68,5 \\
Sulanamayan arazi & $96.516,2$ & 25,5 \\
Sulanan arazi & $116.420,2$ & 31 \\
\hline
\end{tabular}

Van ili tarım arazisi 374.384,2 ha olmakla birlikte bunun yaklaşık \%26'sı nadas bırakılmaktadır. Yarı kurak ve kurak bölgelerde nadasa bırakılma nedeni genel olarak yağışın yetersizliği, yağışa bağlı olarak da sulama suyunun yetersizliğidir. Bu yüzden nadasa bırakılan alanlara yeterli suyun sağlanması durumunda tarım arazisi olan alanın tamamına yakını sulanabilir nitelikte arazi konumuna geçecektir.

Van ilinde sulama amaçlı olarak Zernek barajı, Koçköprü barajı ve Sarımehmet barajı bulunmakta ve Morgedik barajı da inşaat halindedir (Şen ve Saygın 2008; Elp ve Şen 2009; Anonim 2015b) (Çizelge 3). Sulama amaçlı olarak Emek göleti, Morçiçek göleti, Sıhke göleti, Genişgöl göleti, Gölegen göleti, Bahçesaray- Altındere göleti, Bostaniçi göleti aktif olarak kullanılmakta olup inşaat halinde de Aşağ Tulgalı göleti bulunmaktadır (İpek 2007; Anonim 2016a) (Çizelge 4). Ayrıca Keşiş gölü, Akgöl, Kazgölü, Hasantimur gölü, Erçek gölü, Süphan gölü, Hıdırmenteş gölü vardır. Bu baraj göl ve göletlere bağlı olarak 12 adet sulama tesisi bulunmaktadır. Bununla birlikte Van ilinde önemli sayılabilecek Bendimahi çayı, Hoşap çayı, Karasu çayı, Zilan deresi, Deliçay, Memedik çayı, Kotur çayı, Çatak deresi İrşad çayı, Kırkgeçit deresi, Mira çayı ve Kurubaş çayı gibi çok sayıda yüzeysel kaynakta bulunmaktadır (Anonim, 2015b). Ayrıca Van ilinde resmi kayıtlar dâhilinde 283 adet yeraltısuyu sondaj kuyuları bulunmaktadır. Yeraltı suyu sondaj kuyularından çıkan suyun 18, $1 \mathrm{hm}^{3}$ 'ü sulama amaçlı kullanılmaktadır (Anonim $2015 b ; 2016 a)$.

Çizelge 3. Van İlinde sulamada kullanılan barajlar

\begin{tabular}{llll}
\hline Barajın adı & Akarsu & Göl hacmi $\mathbf{( h m}^{\mathbf{3}} \mathbf{)}$ & Sulama alanı (ha) \\
\hline Zernek & Engil çayı & 105,76 & 11.300 \\
Koçköprü & Zilan çayı & 86 & 9.295 \\
Sarımehmet & Karasu çayı & 133,37 & 17.700 \\
Morgedik & Deliçay & 97,58 & 17.574 \\
\hline
\end{tabular}

Çizelge 4. Van İli sulamada kullanılan önemli göletler

\begin{tabular}{llcc}
\hline Göletin adı & Akarsu & Depolama hacmi $\left.\mathbf{( h m}^{\mathbf{3}}\right)$ & Sulama alanı (ha) \\
\hline Emek & Fakir Musa deresi & 0,67 & 124 \\
Morçiçek & Kapan deresi & 2,223 & 430 \\
Sihke & Akköprü deresi & 11,062 & 1430 \\
Genişgöl & - & 17 & 704 \\
Gölegen & Gölegen çayı & 1,39 & 349 \\
Aşağı Tulgalı & Beyaz deresi & 0,558 & 169 \\
Bahçesaray- Altındere & - & $-*$ & 178 \\
Bostaniçi & - & - & - \\
\hline
\end{tabular}

*: kayitlarda veri bulunmamaktadır.

Van iline ait tüm atıkların Sıhke göletine çok yakın bir noktada toplanıyor olmasından kaynaklı kirlilik Sıhke göletinin son yıllarda kirlilik oranı artış göstermiştir. Önlem alınmadığı takdirde çok yakın bir zamanda sulama suyu olarak kullanılamaz hala gelmesi aşikârdır. Ayrıca atıklardan toprağa olan sızıntı yüzünden yeraltı suyu kaynakları da kirlenmektedir. Van İl sınırları içerisinde üretim sezonunda aktif olarak kullanılan 11 adet sulama hattı bulunmaktadır (Çizelge 5). 
Çizelge 5. Van İli Sulama hatları (Anonim 2016a)

\begin{tabular}{lcc}
\hline Sulamanın adı & Sulama alanı (ha) & Sulanan alan (ha)(2015 yılı) \\
\hline Van Karasu Sulaması & 17700 & 2059 \\
Van Sulaması & 7500 & 1146 \\
Erciş Sulaması & 2800 & 1318 \\
Erciş- Koçköprü sağ sahil sulaması & 9295 & 1935 \\
Muradiye Sulaması & 6400 & 885 \\
Gürpınar+Gevaş Sulaması & 13005 & 768 \\
Erciş Sol sahil sulaması & 1069 & 100 \\
Özalp Gölegen Göleti ve sulaması & 349 & - \\
Özalp Morçiçek Göleti ve sulaması & 328 & - \\
Özalp Emek Göleti ve sulaması & 124 & - \\
Bahçesaray- Altındere sulaması & 178 & - \\
\hline
\end{tabular}

-: veri alınamamıştır.

Özalp Gölegen, Özalp Morçiçek, Özalp Emek ve Bahçesaray- Altındere sulama hatlarında sulama tarifesi uygulanmadığ i için veri alımı olmamıştır. İl genelindeki sulama hatlarının tamamında açık trapez kanal ile su iletimi sağlanmaktadır. Sulama hatlarından Van Karasu, Erciş ve Erciş-Koçköprü sağ sahil sulamalarını Sulama Birliği; Van, Muradiye ve Gürpınar-Gevaş sulamasını da Devlet Su İşleri tarafından işletilmektedir. Ayrıca Van iline sulama suyu sağlayan Zernek barajından (2adet), Koçköprü barajından ( 2 adet) ve Sarımehmet barajından (1adet) hidroelektrik enerji üretimi yapılmaktadır.

Su Kirliliği Kontrolü Yönetmeliğine göre yüzeysel sular yüksek kaliteli su (1. sınıf; Toplam koliform 100/100 ml), az kirlenmiş su (2. sınıf; Toplam koliform 20000/100 ml), kirli su (3. sınıf) ve çok kirlenmiş su (4. sınıf) olarak değerlendirilmektedir (Anonim 2004). Alişarlı ve ark., (2007) yılında yaptıkları çalışmada Van bölgesi sularının (içme-kullanma, kuyu, kaynak-çeşme ve akarsu) mikrobiyolojik kirlilik durumlarını incelemişlerdir. Çalışma sonunda Van bölgesi derelerinin su kalitesinin SKKY'ne göre 2. Sınıf su olduğunu bildirmişlerdir.

Zengin (2008), yapmış olduğu çalışmada 16 (göle dökülmeden önce yedi, birleştiği nokta beş, şehir kanalizasyonu iki, sanayi atıkları iki) istasyondan bir yıl boyunca her mevsim periyodik olarak su numuneleri almış ve analiz etmiştir. Çalışma sonunda ortaya çıkan verileri 'KSKSKK Kıta içi Su Kaynaklarının Sınıflarına Göre Kalite Kriterleri'ne göre değerlendirmiştir. Alınan numunelerde tespit edilen ağır metal seviyelerinin sıralanışı $\mathrm{Fe}>\mathrm{Mn}>\mathrm{Pb}>\mathrm{Cr}>\mathrm{Zn}>\mathrm{Cd}$ olarak sıralanmıştır. Ağaoğlu ve arkadaşları (2007)'nın yapmış olduğu çalışmada Van merkez ve ilçelerinden kuyu, dere, musluk, depo, çeşme gibi kaynaklardan alınan 366 numune de flor durumlarının belirlenmesi amaçlanmıştır. Çalışmadan elde edilen veriler Su Kirliliği Kontrolü Yönetmeliğine göre değerlendirildiğinde Van ili ve ilçelerinin sularında flor etkisinin bulunmadığı, flor düzeyleri bakımından 1. sınıf su olduğu belirtilmiştir.

\section{Arıtılmış Atık Su Potansiyeli}

Temiz su kaynaklarının yetersizliği ve varolan kaynaklarımızın kirletilmemesi için arıtılmış atık suyun alternatif sulama suyu olarak kullanılması fikri gün geçtikçe ön plana çıkmaktadır (Çakmakcı ve ark. 2016). Arıtılmış atık suyun gerekli önlemler ve koşullar sağlandığında sulama suyu olarak kullanılmasında herhangi bir sıkıntının olmayacağı bilinmektedir. Arıtılmış atık suyun kullanımında dikkat edilmesi gereken en önemli hususlardan biri endüstri atık sularının sulama vb. kullanımlarıdır. Çünkü endüstri arıtılmış atık sularının içerisinde bulunan fazla miktardaki ağır metal iyonları bitkilerde zehirli etki yapabilmektedir. Bu yüzden arıtılmış atık suyun arıtım mekanizmasının ve arıtılmış atık suyun içeriğinin bilinmesi, sulama için de özellikle evsel nitelikli arıtılmış atık suyun kullanılması gerekmektedir (Çakmakci ve Ucar 2014).

Van ili kanalizasyon hattı ile yıllık 60 milyon ton atık su göle ve akarsulara deşarj edilmektedir. Bu suyun yaklaşık 34 milyon tonu ildeki mevcut arıtma tesisleri tarafından arıtılarak deşarjı sağlanmaktadır (TUiK 2014). Van Su ve Kanalizasyon İdaresi Genel Müdürlüğü'nün 2016 yılı için yapacağı çalışmalar dâhilinde 138 bin $500 \mathrm{~m}$ kanalizasyon hattı yapım ve onarımın olacağını ayrıca Bahçesaray, Çatak, Gürpınar, Saray, Muradiye ve Çaldıran Atık Su Tesisi için yeni projeler ve başvuruların olacağını bildirmiştir (Anonim 2016b). Van ilinde aktif olarak çalışan 5 adet arıtma tesisi (Van merkez, Erciş- 
Çelebibağ, Başkale, Edremit, Gevaş), inşaat halinde olan 2 adet arıtma tesisi (Erciş-Merkez ve Özalp), ihalesi yapılmış olan 2 adet (Bahçesaray ve Saray) ve ihale aşamasında 3 adet (Muradiye, Çatak ve Gürpınar) arıtma tesisi bulunmaktadır (Çizelge 6).

Çizelge 6. Van ili Atık su arıtma tesislerinin durumu (Anonim 2014; 2016a,c)

\begin{tabular}{|c|c|c|c|}
\hline Bulunduğu yer & Durumu & Mevcut kapasitesi (m³/gün) & Hizmet verdiği nüfus \\
\hline Van & Faaliyette & 69.120 & 350.000 \\
\hline Edremit & Faaliyette & 10.400 & 105.505 \\
\hline Bahçesaray & İhalesi yapılmış & $-*$ & 16.819 \\
\hline Başkale & Faaliyette & 2506 & 17.700 \\
\hline Çatak & İhale aşamasında & - & 23.440 \\
\hline Erciş-Çelebibağ & Faaliyette & 2992 & 81.212 \\
\hline Erciş-Merkez & İnşaat aşamasında & 30.936 & 81.212 \\
\hline Gevaş & Faaliyette & 2402 & 11.028 \\
\hline Gürpinar & İhale aşamasında & - & 38.811 \\
\hline Muradiye & İhale aşamasında & - & 51.340 \\
\hline Özalp & İnșaat aşamasında & 2.481 & 11.069 \\
\hline Saray & İhalesi yapılmış & - & 22.793 \\
\hline
\end{tabular}

*: kayitlarda veri bulunmamaktadır.

Van ilinde 1 adet Organize Sanayi Bölgesi bulunmaktadır. Sanayi Bölgesinin 1 adet Atık su Arıtma Tesis mevcuttur. Van ili belediyelerine ait arıtma tesislerinin bazıları tam kapasite ile çalışmamakta ve bakımsılıktan dolayı da istenilen arıtım verimi elde edilememektedir.

\section{Sonuç ve Öneriler}

Gün geçtikçe nüfus artmakta buna bağlı olarak doğal tüketimimiz olan su ihtiyacımızda artmaktadır. Van ilinde sulama amaçlı baraj, göl-gölet ve sulama tesisleri bulunmaktadır. Fakat yoğun sulama sezonu olan Haziran, Temmuz ve Ağustos aylarında sulama suyunun araziye ulaştırılamaması, çiftçinin suyu düzensiz ve bilinçsiz kullanması, toprağın özelliklerine uygun sulama yönteminin seçilmemesi gibi sebepler yüzünden sulama suyu yetersiz kalmaktadır.

Sulama suyunun yetersiz kaldığı yerlerde arıtılmış atık suyun sulama suyu olarak kullanılması gerekmektedir. Arıtılmış atık suyun kullanılmasıyla sadece sulama suyu sağlanmış olmayıp aynı zamanda arıtılmış atık su içerisindeki besin elementleri sayesinde kimyasal gübre tüketimi azalacaktır. Arıtılmış atık su kullanımı ile arıtma tesisleri çıkış sularının da göl- gölet-baraj vb. alıcı ortamlara bırakılması ve kaynaklarımızın kirletilmesi, yok olup gitmesi engellenmiş olacaktır.

Van ilinin öncelikli sorunlarından biri de alt yapı ve kanalizasyon sorunudur. Mevcut kanalizasyon sistemi nüfusun yaklaşık \%60-70'ne hizmet vermektedir. Bu oran da atığın iletilmesi için yetersiz kalmaktadır. Van ilinin atık deposunun yarattığı kirlilik yüzünden hem Sıhke göleti zarar görmekte hem de yeraltı suları kirlenmektedir. $\mathrm{Bu}$ yüzden atık deposunun başka bir alanda planlanması önem arz etmektedir. Sonuç olarak; Van ilinde varolan su kaynakları korunmalı, çiftçiler gerekli seminer, toplantı vb. etkinliklerle bilinçlendirilmeli, yeni su kaynağı olarak da arıtılmış atık suyun sulamada kullanımı için Üniversiteler, Kamu Kuruluşları ile işbirliği halinde olunmalıdır.

\section{Kaynaklar}

Ağaoğlu S, Alişarlı M, Alemdar S, Dede (2007). Van Bölgesi İçme ve Kullanma Sularında Nitrat ve Nitrit Düzeylerinin Araştırılması. Yüzüncü Y1l Üniversitesi Veteriner Fakültesi Dergisi, 18(2):17-24.

Akın M, Akın G (2007). Suyun Önemi, Türkiye'de Su Potansiyeli, Su Havzaları ve Su Kirliliği. Ankara Üniv. Dil ve Tarih- Coğrafya Fakültesi Dergisi, 47(2):105-118.

Alişarlı M, Ağaoğlu Sema, Alemdar S (2007). Van Bölgesi İçme ve Kullanma Sularının Mikrobiyolojik Kalitesinin Halk Sağlığı Yönünden İncelenmesi. Yüzüncü Yıl Üniversitesi, Veteriner Fakültesi Dergisi 18(1): 67-77.

Anonim (2004). Su Kullanım Kontrol Yönetmeliği. Mevzuat Geliştirme ve Yayın Genel Müdürlüğü. Mevduat Bilgi Sistemi. 
Anonim (2006). 2006 Van ili Sanayi Envanteri.

Anonim (2014). Van ili 2013 yılı Çevre durum raporu. T.C. Van Valiliği Çevre ve Şehircilik İl Müdürlüğü, Çevre Yönetimi ve Denetimi Şube Müdürlüğü.

Anonim (2015a). Meteoroloji Genel Müdürlüğü. http://www.mgm.gov.tr Erişim tarihi: 25.06.2016

Anonim (2015b). Van ili 2013 yılı Çevre durum raporu. T.C. Van Valiliği Çevre ve Şehircilik İl Müdürlüğü, Çevre Yönetimi ve Denetimi Şube Müdürlüğü.

Anonim (2016a). Van ili 2015 yılı Çevre durum raporu. T.C. Van Valiliği Çevre ve Şehircilik İl Müdürlüğü, Çevre Yönetimi ve Denetimi Şube Müdürlüğü.

Anonim (2016b). http://www.vaski.gov.tr Erişim Tarihi: 21.07.2016

Anonim (2016c). Van Su ve Kanalizasyon İdaresi Genel Müdürlüğü 2015 mali yılı faaliyet raporu. http://www.vaski.gov.tr/resimler/files/VASK\%C4\%B0_Faaliyet.pdf erişim tarihi: 10.08.2016

Çakmakci T, Ucar Y (2014). Efficiency of canola (Brassica napus L.) as an accumulator of heavy metals in wastewater applications. Polish Journal of Environmental Studies, 23(6): 2309-2313.

Çakmakcı T, Uçar Y, Erbaş S (2016). Atık Su Uygulamalarının Konola'da (Brassica napus L.) Yağ Oranı ve Yağ Asitleri Kompozisyonuna Etkisi. YYÜ Tar. Bil. Derg. (YYU J Agr Sci), 145-151.

Çimrin KM, Boysan S (2006). Van Yöresi Tarım Topraklarının Besin Elementi Durumları ve Bunların Bazı Toprak Özellikleri ile İlişkileri. YYÜ Tar. Bil. Derg. (YYU J Agr Sci) 16 (2): 105-111.

Elp M, Şen F (2009). Biological Properties of Capoeta capoeta (Guldenstaedt, 1779) Population Living in Karasu Stream (Van, Turkey), Medwell Publishing. Journal of Animal and Veterinary Advances (1): 139-142.

Ertek A, Gençoğlan C, Tüfenkçi Ş (2000). Van Yöresinde Toprak ve Su Kaynakları ile Sulama Uygulamalarına İlişkin Sorunlar ve Çözüm Önerileri. Fen ve Mühendislik Dergisi, 3(1):72-83.

Ertek A, Şensoy S, Küçükyumuk C, Gedik I (2004). Irrigation frequency and amount affect yield components of summer squash (Cucurbita pepo L.). Agricultural Water Manag., 67(1)63-76.

Ertek A, Şensoy S, Gedik I, Küçükyumuk C (2006). Irrigation scheduling based on pan evaporation values for cucumber (Cucumissativus L.) grown under field conditions. Agricultural Water Management, 81(1), 159-172.

Eryılmaz H, İpek Şİ, Yalçın Çelik B (2014). Borçka Baraj Gölü (Artvin) Su Kalitesinin Araştırılması. Dumlupınar Üniversitesi Fen Bilimleri Enstitüsü Dergisi. 4:1-8.

Gözütok E (1993). Van Tarım İl Müdürlüğü Brifing Dosyası.

Kaydan D, Yağmur M (2008). Van Ekolojik Koşullarında Bazı Ekmeklik Buğday (Triticum aestivum L.) Çeşitlerinin Verim ve Verim Öğeleri Üzerine Bir Araştırma. Ankara Üniversitesi Ziraat Fakültesi Tarım Bilimleri Dergisi. 14(4): 350-358.

İpek İŞ (2007). Determining of Drought Probability and Drought Risk for Different Water Management Scenarios. International Congress on River Basin Management. Pp: 800-814.

Sağlam MT, Bellitürk K (2003). Su Kirliliği ve Toprak Üzerindeki Etkisi. Alatarım. 2(1): 46-49.

Sensoy S, Ertek A, Gedik I, Kucukyumuk C (2007). Irrigation frequency and amount affect yield and quality of field-grown melon (Cucumis melo L.). Agricultural Water Manag., 88(1), 269-274.

Şen F, Saygın F (2008). Biological Properties of Chup (Leuciscus cephalus L., 1758) in Karasu Stream (Mus/Turkey). Medwell Publishing. Journal of Animal and Veterinary Adv. 7(8):1034-1037.

Tekinel O (2004). Sulu Tarımında Problemler ve Çözüm Yolları. 21. Yüzyılda Su Sorunu ve Türkiye (Fırsatlar-Zorluklar, Güçlü ve Zayıf Yanlarımız). 2000'li Yıllarda Türkiye Stratejik, Sosyal ve Ekonomik Araştırmalar Vakfi, Ankara.

TUİK (2014). Tarım İstatistikleri. http://www.tuik.gov.tr. Erişim tarihi: 14.11 .2015

Turan F (2002). Türkiye'nin Su ve Toprak Kaynakları Potansiyeli ve Gelişimi. Türkiye Mühendislik Haberleri. Sayı 420-421-422 (4-5-6).

Tüfenkçi Ş, Sönmez F, Şensoy Gazioğlu Rİ (2009). Van İli Bağlarının Beslenme Durumlarının Belirlenmesi. Harran Üniversitesi Ziraat Fakültesi Dergisi, 13(4) :13-22.

Zengin O (2008). Van Gölü ve Gölü Besleyen Kaynaklarda Ağır Metal Kirliliğinin Araştırılması. Yüksek Lisans Tezi. Gazi Üniversitesi, Fen Bilimleri Enstitüsü. Ankara. 